\title{
Finite Element Analysis of a Natural Fiber (Maize) Composite Beam
}

\author{
D. Saravana Bavan and G. C. Mohan Kumar \\ Department of Mechanical Engineering, National Institute of Technology, Srinivasnagar, Surathkal, Mangalore, \\ Karnataka 575025, India \\ Correspondence should be addressed to D. Saravana Bavan; saranbav@gmail.com
}

Received 31 August 2012; Revised 29 November 2012; Accepted 30 November 2012

Academic Editor: Run-Cang Sun

Copyright (C) 2013 D. S. Bavan and G. C. M. Kumar. This is an open access article distributed under the Creative Commons Attribution License, which permits unrestricted use, distribution, and reproduction in any medium, provided the original work is properly cited.

\begin{abstract}
Natural fiber composites are termed as biocomposites or green composites. These fibers are green, biodegradable, and recyclable and have good properties such as low density and low cost when compared to synthetic fibers. The present work is investigated on the finite element analysis of the natural fiber (maize) composite beam, processed by means of hand lay-up method. Composite beam material is composed of stalk-based fiber of maize and unsaturated polyester resin polymer as matrix with methyl ethyl ketone peroxide (MEKP) as a catalyst and Cobalt Octoate as a promoter. The material was modeled and resembled as a structural beam using suitable assumption and analyzed by means of finite element method using ANSYS software for determining the deflection and stress properties. Morphological analysis and X-ray diffraction (XRD) analysis for the fiber were examined by means of scanning electron microscope (SEM) and X-ray diffractometer. From the results, it has been found that the finite element values are acceptable with proper assumptions, and the prepared natural fiber composite beam material can be used for structural engineering applications.
\end{abstract}

\section{Introduction}

Natural fibers are becoming popular in recent times especially in composites sector because they have lot of advantages over traditional fibers in terms of low cost, low density, biodegradable and easily processed $[1,2]$. Natural fibers are mainly classified into plant fibers, animal fibers, and mineral fibers as shown in Figure 1. Most commonly, composite materials have a bulk phase, which is continuous, called the matrix, and one dispersed, noncontinuous, phase called the reinforcement, which is usually harder and stronger. The reinforcement material can be of fibers, particulates, or flakes. The concept of composites is that the bulk phase accepts the load over a large surface area and transfers it to the reinforcement, which being stiffer, increases the strength of the composite. In biocomposites, natural fiber act as reinforcement material, and the matrix material can be of synthetic polymer or a biopolymer [3]. Natural fibers are cheap, abundant, and renewable and can be produced at low cost in many parts of the developing world. They are strong and stiff, and due to their low densities, it has the potential to produce composites with similar specific properties to those of E-glass fibers [4].

Natural fibre composites (biocomposites) are primarily composed combination of cellulose, hemicellulose, and lignin, which can be derived not only from leaf (e.g., sisal), bast (e.g., flax and hemp), seed (e.g., cotton), and fruit (e.g., coir), but also from other sources such as chicken feathers $[1,2]$, and these natural fibres offer a number of advantages over existing synthetic fibres (e.g., carbon and aramid fibres). From an environmental perspective, natural fibres are biodegradable and are carbon positive since they absorb more carbon dioxide than they produce. Natural fibres also possess a number of advantages in terms of specific material properties as shown in Table 1. The bast and leaf fibres lend mechanical support to the plants stem or leaf, respectively; examples for these kinds of fibres include flax, hemp, jute, and ramie.

The surfaces of natural fibres are uneven and rough which provides good adhesion to the matrix in a composite material. 


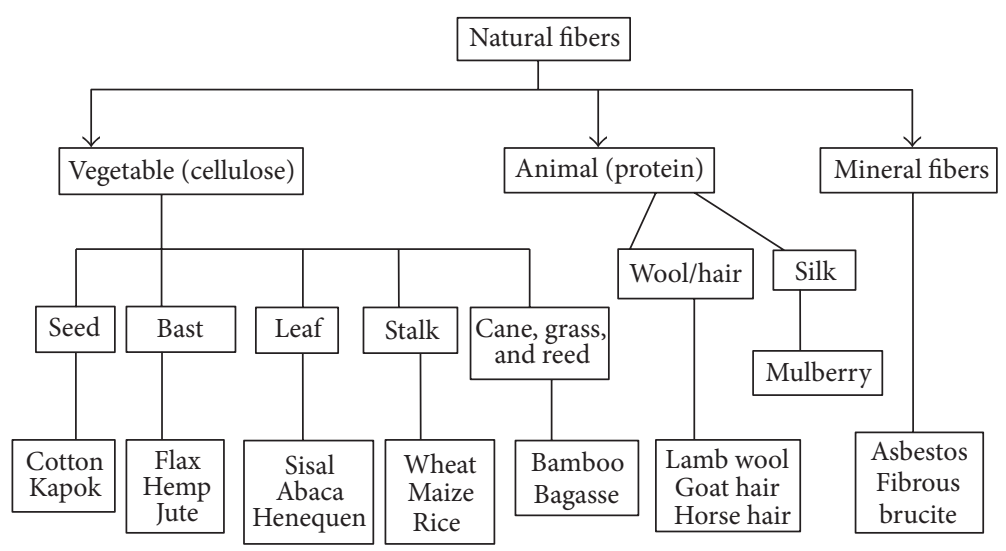

FIgURE 1: Classification of natural fibers $[1,2]$.

TABLE 1: Few properties of natural and synthetic fibers $[1,2]$.

\begin{tabular}{lccccc}
\hline Fibers & Density $\left(\mathrm{g} / \mathrm{cm}^{3}\right)$ & Tensile strength $(\mathrm{MPa})$ & $E$-modulus $(\mathrm{GPa})$ & Elongation at failure (\%) & Moisture absorption \\
\hline E-glass & 2.55 & $2400-3500$ & 73 & 3 & - \\
Aramid & 1.4 & $3000-3450$ & $63-67$ & $3.3-3.7$ & - \\
Carbon & 1.4 & 4000 & $230-240$ & $1.4-1.8$ & - \\
Flax & 1.4 & $800-1500$ & $60-80$ & $1.2-1.6$ & 7 \\
Hemp & 1.4 & $550-900$ & 70 & 1.6 & 8 \\
Jute & 1.46 & $400-800$ & $10-30$ & 44 & 2 \\
Ramie & 1.5 & 500 & 6 & $15-25$ & $12-17$ \\
Coir & 1.25 & 220 & 38 & $2-3$ & 10 \\
Sisal & 1.33 & $600-700$ & 12 & $3-10$ & $8-25$ \\
Cotton & 1.51 & 400 & & & 11 \\
\hline
\end{tabular}

The specific mechanical properties of natural fibres have high significance for their utilization in composites. In natural fibre-reinforced composites, fibre acts as reinforcement and exhibits high tensile strength and stiffness. The mechanical properties of reinforcement (fibres) have direct relation with the tensile strength and stiffness of the composite. The selection of suitable reinforcing fibres follows certain criteria such as, thermal stability, fibre-matrix adhesion, long time behavior, elongation at failure, and moreover price and processing costs. The majority of biocomposites presently used are in the automotive, construction, furniture, and packaging industries. The techniques used to manufacture biocomposites are based largely on existing techniques for processing plastics or composite materials. These include press moulding, hand lay-up, filament winding, pultrusion, extrusion, injection moulding, compression moulding, resin transfer moulding, and sheet moulding compound methods.

Composite materials used for structural purposes often have low densities, resulting in high stiffness to weight and high strength to weight ratios when compared to traditional engineering materials [5]. In addition, the high fatigue strength to weight ratio and fatigue damage tolerance of many composites also makes an attractive option. Composite mechanical properties are strongly influenced by the mechanical properties, distribution of the fibers, and matrix, and well as the efficiency of stress transfer between these two components [6]. Polymer composites are widely used in many major engineering structural applications. The matrix serves for mainly two important purposes; namely, it bonds the fibrous phase, and under an applied force, it deforms and distributes the stress to the high-modulus fibrous constituent [7]. The ultimate properties of the composites depend on many properties such as constituents, size, and shape of the individual reinforcing fibres or particles, structural arrangement and distribution, relative amount of each constituent, and the interface between matrix and reinforcement $[8,9]$.

The present work is focused on using maize stalk fiber as a natural fiber and unsaturated polyester (thermoset polymer) as a matrix processed by a simple hand lay-up procedure to produce a composite beam material. Later, the mechanical properties of the material are analyzed using ANSYS (commercially finite element method simulation software) with proper assumptions. Morphological analysis and XRD analysis of the stalk fiber were also carried out.

\section{Experimental Work}

2.1. Hand Lay-Up Method. Hand Lay-up technique was employed for the preparation of the natural fiber-reinforced polymer composite; mould made of mild steel was used with dimensions of $80 \times 40 \times 10 \mathrm{~mm}$ as shown in Figure 2. This 


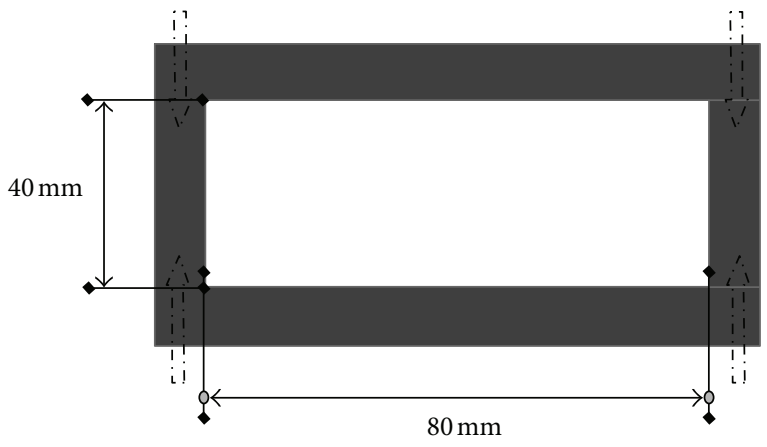

Figure 2: Schematic of hand lay-up mold.

TABLE 2: Matrix characteristics of unsaturated polyester resin.

\begin{tabular}{lcc}
\hline Sl No & Factors & Value \\
\hline 1 & Appearance & Clear \\
2 & Colour & Pale yellow \\
3 & Viscosity @ $30^{\circ} \mathrm{C}$ & $430 \mathrm{mPa}-\mathrm{s}$ \\
4 & Gel time @ $30^{\circ} \mathrm{C}$ (minutes) & (Brook field viscometer) \\
\hline
\end{tabular}

method is the cheapest method of manufacturing, but it has some disadvantages such as long curing time and low production rate, and further the quality of the composite depends on the skill of the worker. The stalk fibres were placed in the mold evenly, and thermosetting resin is mixed with promoter and catalyst. Mold release agent is applied all over the mold surface, and a brush or roller is used to wrap layering process of the fibres. Layers of the fibres impregnated with the resin are used to build up the require thickness.

2.2. Materials. Maize stalk fibers are collected from a local farm field, Davangere (Karnataka), India, and general purpose unsaturated polyester resin (thermosetting polymer), catalyst (methyl ethyl ketone peroxide), and Promoter (Cobalt Octoate) were purchased from Vinayaka Chemicals, Private Limited, Bangalore (Karnataka), India. Unsaturated polyester resins are commercial thermoset polymers which contain a number of carbon, $\mathrm{C}=\mathrm{C}$ double bonds. Unsaturated means that the resin is capable of being cured from a liquid to a solid state. Typical unsaturated polyester may be prepared by reacting an unsaturated dibasic acid, maleic anhydride, with a glycol and ethylene glycol. Matrix characteristics of unsaturated polyester resin are shown in Table 2.

2.3. Alkali Treatment. Alkali treatment is the simplest method of chemical treatment of fibers; it leads to the increase in the amount of amorphous cellulose at the expense of crystalline cellulose. The important modification occurring here is the removal of hydrogen bonding in the network structure. The following reaction takes place as a result of alkali treatment

$$
\text { Fiber- } \mathrm{OH}+\mathrm{NaOH} \longrightarrow \text { Fiber- } \mathrm{O}^{-} \mathrm{Na}^{+}+\mathrm{H}_{2} \mathrm{O}
$$

TABLE 3: Chemical composition of maize stalk fibers.

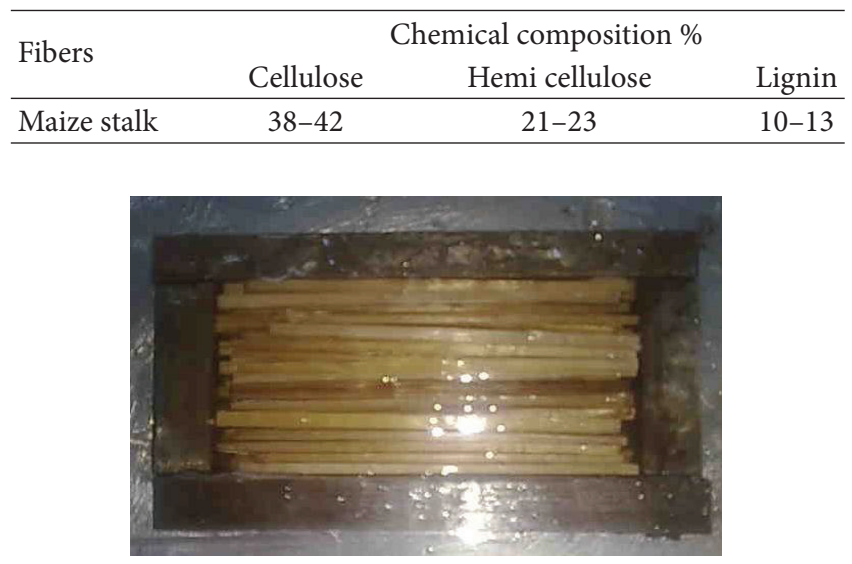

FIGURE 3: Maize fibers with unsaturated polyester resin placed in the mould.

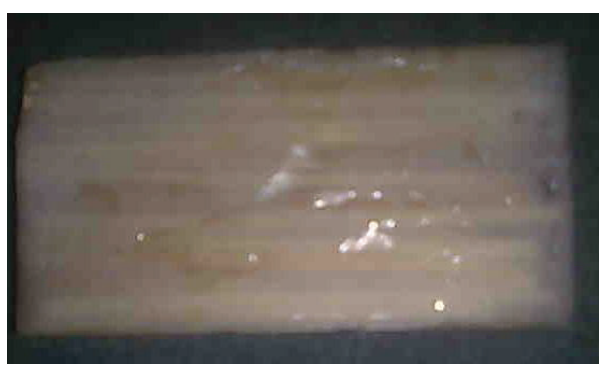

FIgURE 4: Specimen of maize fiber composite beam.

2.4. Preparation of Maize Stalk Beam. Maize stalk fibers are cleaned thoroughly and later chopped in tiny sizes, and the chemical compositions of maize stalk fibers are shown in Table 3 . These fibers are chemically treated by alkali method with $5 \%$ sodium hydroxide $(\mathrm{NaOH})$ and are thoroughly rinsed with distilled water for 2 to 3 times and placed in oven for 70 minutes at $60^{\circ} \mathrm{C}$. The polymer matrix is mixed with catalyst and promoter. The resins are thoroughly mixed at appropriate proportions and processed by hand lay-up technique to produce a composite beam. The matrix must be liquid to ensure good wetting and impregnation of fibres during formation. A small beam mould is prepared and made to consist of maize stalks fibers of approximate length of $80 \mathrm{~mm}$ and placed in a unidirectional manner as shown in Figures 3 and 4.

\section{Finite Element Model and Analysis}

3.1. Finite Element Analysis. Fiber composites consist of fiber and matrix phases, and the mechanical behavior of the composites is much determined by the fiber and matrix properties. Microstructures such as fiber shape, fiber array, and volume fraction of fibers are also more important in determining the mechanical properties [10]. Micromechanical models have been used to predict the properties starting from the intrinsic properties and their constituents [11], and these models show that the fibre strength is not 
being completely employed as a result of poor fibre matrix interfacial adhesion and fiber length.

The material is modeled using certain assumptions and analyzed for mechanical properties with finite element method software (ANSYS). The composite material is assigned as unidirectional composite by assuming some properties that are given below.

Some of the assumptions used for the analysis work have been gathered by the literature [12-17].

(1) Fibers are not porous.

(2) The material property for all the constituents are attributed as isotropic material for both volumes.

(3) Fibers are uniform in properties with diameter.

(4) Interphase bonding is maintained between fibers and matrix.

(5) Perfect bond between fiber and matrix and no slippage.

(6) Fibers are arranged in unidirectional manner and perfectly aligned.

(7) Composite material is free of voids.

The interface between fibre and matrix is also an interface that serves to transfer externally applied loads to the reinforcement via shear stresses over the interface. Controlling the strength of the interface is imperative. Clearly, good bonding is essential if stresses are to be adequately transferred to the reinforcement and hence provide a true reinforcing function. Another important mechanical property is toughness or the ability of an engineering material to resist the propagation of cracks. This occurs in composites by virtue of their heterogeneous structure. It is important that under certain circumstances interfacial adhesion breaks down so as to allow various toughening mechanisms to become operative. These mechanisms include crack blunting as proposed by [18] and various energy absorption processes such as the frictional sliding of debonded fibre fragments within the matrix, fibre fracture, and the creation of new crack surfaces [19].

The finite element method (FEM) was used to model the behavior of a material on the basis of micromechanical level. The model was assumed to be an isotropic material with a rectangular section of a beam. This section is then modeled in detailed using volume elements to represent the composite. Each element will have an isotropic property and will be positioned corresponding to the fibers, and the mesh regions are coarsely meshed (converged solution).

The composite material consists of fibres aligned in unidirectional manner and modelled as a regular uniform arrangement, as shown in Figures 5, 6, and 7. This model assumed that the fibre is a perfect cylinder of length $l(80 \mathrm{~mm})$ and diameter $d(1 \mathrm{~mm})$ in a matrix as shown in Figures 8 and 9.

The model is treated as a linear isotropic problem. The FEA model is constituted of SOLID 95 elements, used for fibre-matrix structure as shown in Figure 9. The model included the fibre, matrix, and fibre-matrix interface. Nine fibres were modelled to the surrounding matrix. The fibres,

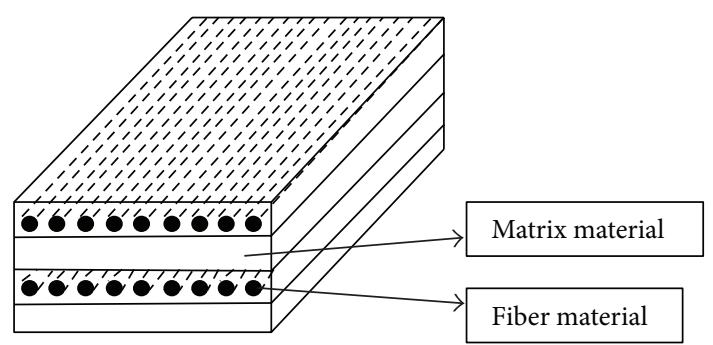

Figure 5: Composite material with fiber and matrix.

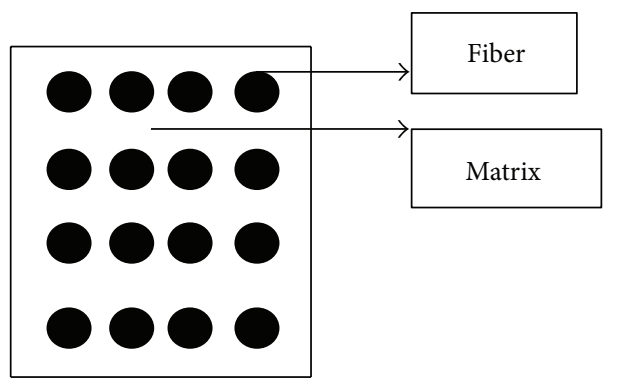

Figure 6: Fiber and matrix region.

with surrounding matrix were selected for stress analysis in this model. These regions were modelled using the coarse mesh (converged solution) as shown in Figure 10 and the load applied of $1 \mathrm{Kg}$ at the top edge of the model.

3.2. Morphology Analysis of Maize Fiber Composites. Morphological analysis of raw maize stalk fiber and alkalitreated maize fiber with unsaturated polymeric resin was carried out by studying scanning electron microscope (SEM). Natural fiber samples were coated with gold using a vacuum sputter coater and analyzed. The morphology changes were observed using Jeol JSM-5600LV electron microscopy with an accelerating voltage of $15 \mathrm{kV}$.

3.3. X-Ray Diffraction (XRD) Analysis of Maize Fiber Composites. The XRD analysis determined the crystallinity of the maize fiber and was used to indicate the dramatic change in the crystallinity of the maize fiber as shown in Table 4 . All the fiber samples were scanned in $2 \theta$ range varying from $10^{\circ}$ to $50^{\circ}$. The spectrum corresponding to maize raw fibers shows the diffraction peaks of amorphous region and crystalline region at the following $2 \theta$ angles at $22.58^{\circ}$ and a high peak nearly at $29.46^{\circ}$. For alkali-treated fibers, same peaks can be observed at $22.44^{\circ}$ and $29.28^{\circ}$. Similarly for the chemically treated fiber with unsaturated polymeric resin, the crystalline region peak at $28.12^{\circ}$ and the amorphous region at $20.36^{\circ}$ were observed. The position of the peak indicates an increase of interplanar distance in relation to fibre treated. This occurs due to generation of disorder when fibre is treated and the patterns for the above materials are similar. 
TABLE 4: Percent crystallinity and crystallinity index for maize stalk fibers.

\begin{tabular}{lcccc}
\hline \multirow{2}{*}{ Maize stalk fiber } & \multicolumn{2}{c}{$2 \theta$ (degree) } & Crystallinity (\%) & Crystallinity index \\
\hline Raw & $I_{\mathrm{C}}$ & $I_{\mathrm{A}}$ & 56.71 & 0.044 \\
Alkali treated & $29.46^{\circ}$ & $22.58^{\circ}$ & 56.61 & 0.233 \\
Chemically treated with unsaturated polymer & $29.28^{\circ}$ & $22.44^{\circ}$ & 58.00 & 0.275 \\
\hline
\end{tabular}

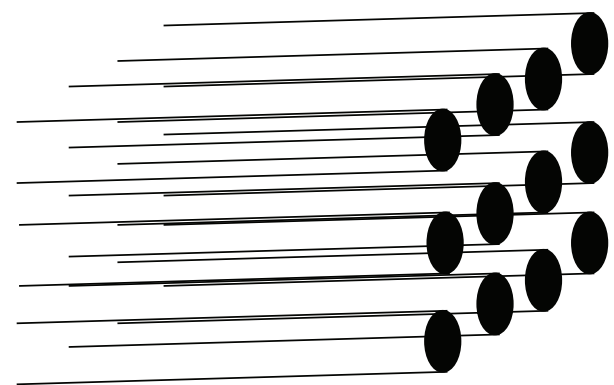

FIgURE 7: Unidirectional aligned fibers.

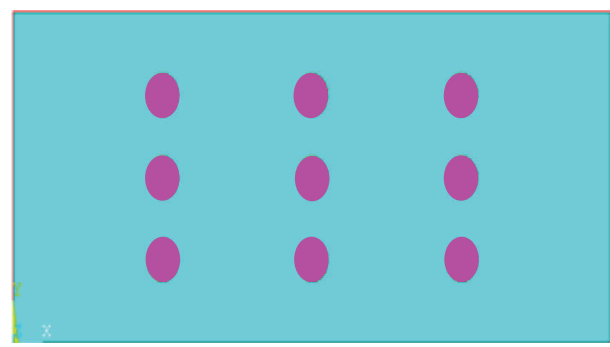

FIGURE 8: FEM model of the composite with fiber and matrix.

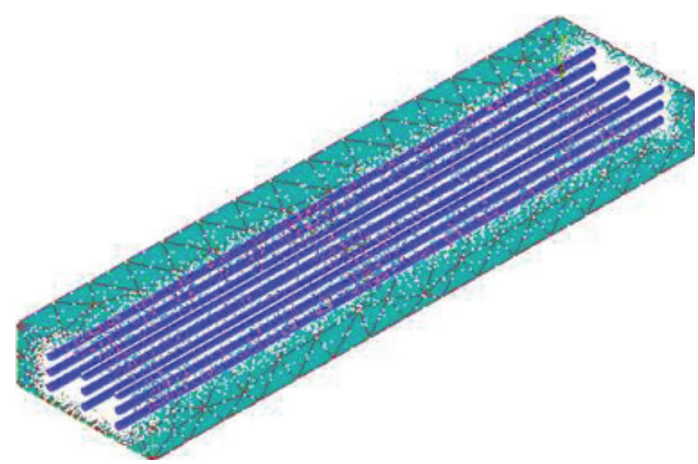

FIGURE 9: 3D model of the composite beam.

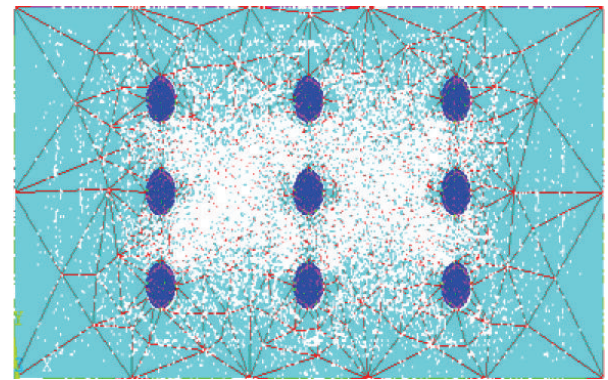

Figure 10: Meshing of fibers and matrix.

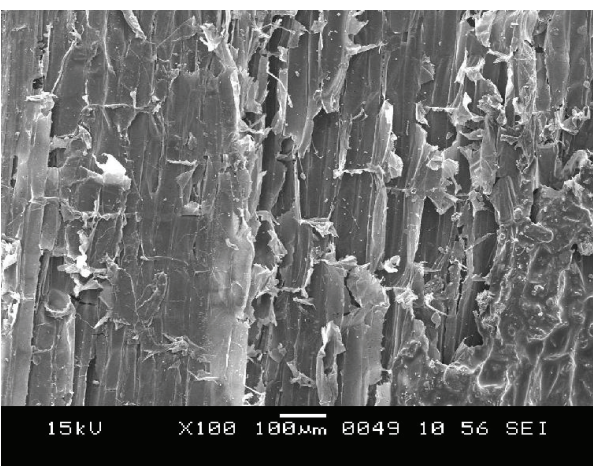

FIGURE 11: SEM image of raw maize stalk fiber surface.

\section{Results and Discussions}

The morphological analysis from scanning electron microscope (SEM) reveals the difference of fibers without treatment and with treatment of chemicals as shown in Figures 11 and 12. The fibers were changed when treated with chemicals, and the crystalline structure of the cellulose is altered; it had a thick layer of protective material and cellular deposits with presence of lumen.

The geometry model was meshed with SOLID 95 elements with calculated nodal displacement fields in $x$ and $y$ directions. Boundary conditions were enforced along the side surfaces and the nodal displacements were enforced along the top face with normal directions. The fibre was taken as an isotropic material with Young's modulus $\left(E_{f}=8.58 \mathrm{GPa}\right)$ for fiber, and $\left(E_{m}=1.3 \mathrm{GPa}\right)$ for the polymeric resin and Poisson ratio of $v_{m}=0.3$. Reinforcement content affects the level of stress and stress distribution in fibre, matrix, and fibrematrix interphase. In this model, the volume fibre content was varying from 20 to $25 \%$.

The fibre content of the composite was an important factor controlling the mechanical properties of the composites. The level of stress in the fibres is lower and in the matrix is higher than in the composite with low fibre content. This means that the load applied to the composite will be carried by the fibre, compared with when there is a lower fibre content present. The deflection in the beam composite is shown in Figure 13 and the stress intensity in Figure 14.

The von Mises stresses are one of the important factors in the FEA model, and they were analysed as shown in Figure 15. It illustrates the stress distribution for a composite material, fibre and interphase, and the exhibited complicated stress distribution. It shows the level of stress in the the fibre matrix regions. There exist two important zones of 


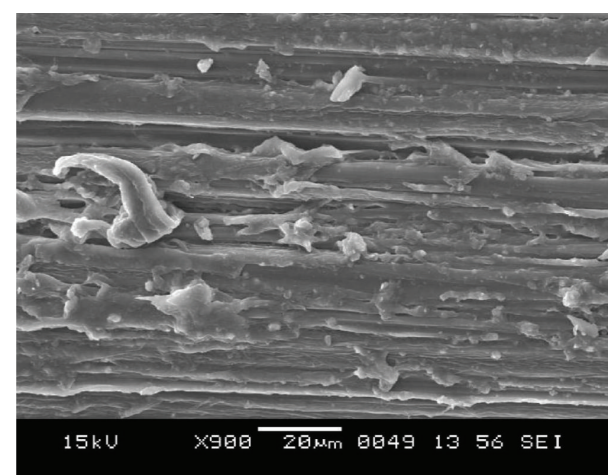

FIGURE 12: SEM image of chemically treated maize stalk fiber surface.

$$
\begin{aligned}
& \text { Nodal solution } \\
& \text { Step }=1 \\
& \text { Sub }=1 \\
& \text { Time }=1 \\
& \text { USUM (Avg) } \\
& \text { RSYS }=0 \\
& \text { DMX }=8.224 \\
& \text { SMX }=8.224
\end{aligned}
$$

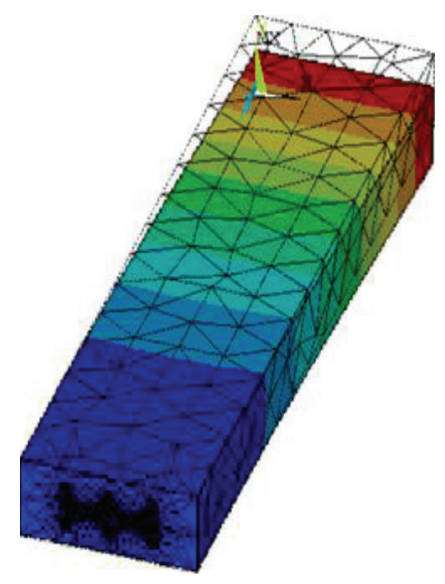

FIGURE 13: Deflection in the composite beam.

stress concentration, they are fibre and fibre-matrix, and the most important stress occurred at the interface region of the composite material. The von Mises stress shows high stress concentration in the fibre and interphase region. Von Mises strain is depicted in Figure 16, and Nodal displacement along $X$-direction is shown in Figure 17.

\section{Conclusions}

From FEM analysis, it is confirmed that there is a possibility of reducing the stress concentration in the matrix and at the fiber interface by increasing the fiber content to an optimum content. More stress deviation in the fiber, matrix, and interface regions of the composite leads to chances of fiber debonding. finite element method software simulation (ANSYS) reveals that there is a need to have certain assumptions for the perfect bonding and also to define interface properties. In the present method, the model is validated using some assumptions because natural fibers
Nodal solution

Step $=1$

$\mathrm{Sub}=1$

Time $=1$

EPTOEQV (Avg)

DMX $=8.224$

$\mathrm{SMN}=0.343 E-04$

SMX $=0.015125$

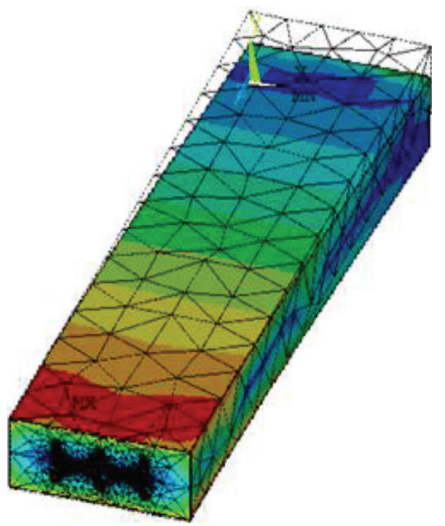

FIGURE 14: Stress intensity in the composite beam.

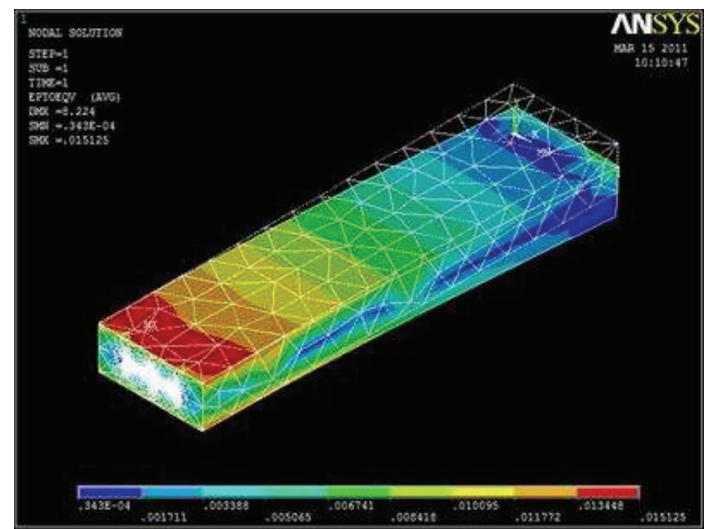

FIgURE 15: Von Mises stress in the composite beam.

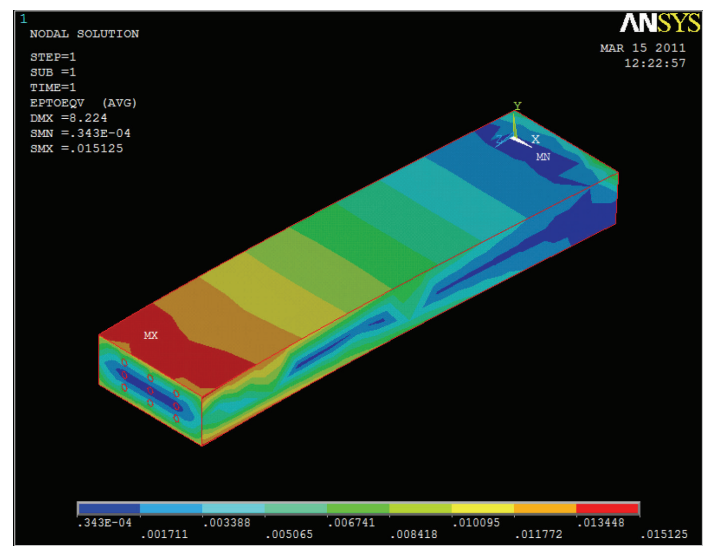

Figure 16: Von Mises strain in the composite beam. 


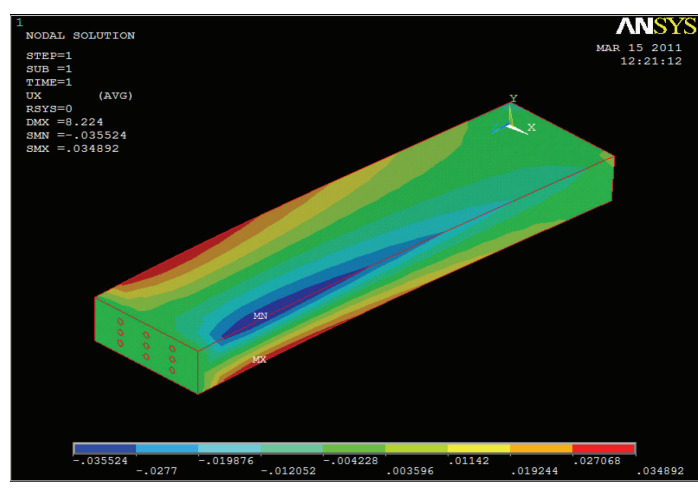

FIGURE 17: Nodal displacement along $X$-direction in the composite beam.

are anisotropy, porosity and the interphase, whose volume will vary with different conditions and fiber arrangements. Hence, the obtained values are predicted values.

\section{Conflict of Interests}

The authors of this paper do not have any conflict of interests.

\section{Acknowledgments}

The authors sincerely thank the local Davangere Farm, Karnataka, India for providing maize stalks and Mr. Syed Fahemullah for his kind help.

\section{References}

[1] A. K. Mohanty, M. Misra, and G. Hinrichsen, "Biofibres, biodegradable polymers and biocomposites: an overview," Macromolecular Materials and Engineering, vol. 276-277, pp. $1-24,2001$.

[2] M. J. John and S. Thomas, "Biofibres and biocomposites," Carbohydrate Polymers, vol. 71, no. 3, pp. 343-364, 2008.

[3] R. P. Wool, Sun, and X. S. Editors, Bio-Based Polymers and Composites, Elsevier, Amsterdam, The Netherlands, 2005.

[4] F. T. Wallenberger and N. Weston, Natural Fibers, Plastics and Composites, Kluwer Academic Publishers, 2003.

[5] M. A. Dweib, B. Hu, A. O’Donnell, H. W. Shenton, and R. P. Wool, "All natural composite sandwich beams for structural applications," Composite Structures, vol. 63, no. 2, pp. 147-157, 2004.

[6] W. D. Callister, Materials Science and Engineering: An Introduction, John Wiley and Sons, New York, NY, USA, 1999.

[7] A. K. Bledzki, V. E. Sperber, and O. Faruk, "Natural and wood fibre reinforcement in polymers," Rapra Review Reports, vol. 13, no. $8,2002$.

[8] A. S. Herrmann, J. Nickel, and U. Riedel, "Construction materials based upon biologically renewable resources-from components to finished parts," Polymer Degradation and Stability, vol. 59, no. 1-3, pp. 251-261, 1998.

[9] R. Ulrich, "Natural fibre reinforced biopolymers as construction materials- new discoveries," in Proceedings of the 2nd Natural Wood and Natural Fibre Composite Symposium, Kassel, Ramagen, Germany, June 1999.
[10] J. L. Tsai and Y. K. Chi, "Effect of fiber array on damping behaviors of fiber composites," Composites Part B, vol. 39, no. 7-8, pp. 1196-1204, 2008.

[11] S. Rao, K. Jayaraman, and D. Bhattacharyya, "Micro and macro analysis of sisal fibre composites hollow core sandwich panels," Composites B, vol. 43, no. 7, pp. 2738-2745, 2012.

[12] M. Bayat and M. M. Aghdam, "A micromechanics based analysis of hollow fiber composites using DQEM," Composites B, vol. 43, pp. 2921-2929, 2012.

[13] I. Balac, K. Colic, M. Milovancevic, P. Uskokovic, and M. Zrilic, "Modeling of the matrix porosity influence on the elastic properties of particulate biocomposites," FME Transactions, vol. 40, pp. 81-86, 2012.

[14] L. J. da Silva, T. H. Panzera, A. L. Christoforo, L. M. P. Durao, and F. A. R. Lahr, "Numerical and experimental analyses of biocomposites reinforced with natural fibres," International Journal of Materials Engineering, vol. 2, no. 4, pp. 43-49, 2012.

[15] A. Le Duigou, P. Davies, and C. Baley, "Interfacial bonding of Flax fibre/Poly(l-lactide) bio-composites," Composites Science and Technology, vol. 70, no. 2, pp. 231-239, 2010.

[16] E. A. Elbadry, M. S. Aly-Hassan, and H. Hamada, "Mechanical properties of natural jute fabric/jute mat fiber reinforced polymer matrix hybrid composites," Advances in Mechanical Engineering, vol. 2012, Article ID 354547, 12 pages, 2012.

[17] T. Behzad and M. Sain, "Finite element modeling of polymer curing in natural fiber reinforced composites," Composites Science and Technology, vol. 67, no. 7-8, pp. 1666-1673, 2007.

[18] J. Cook and J. E. Gordon, "A mechanism for the control of crack propagation in all-brittle systems," Proceedings of the Royal Society A, vol. 282, pp. 508-520, 1964.

[19] D. Hull and T. W. Clyne, An Introduction to Composite Materials, Cambridge University Press, Cambridge, UK, 1996. 

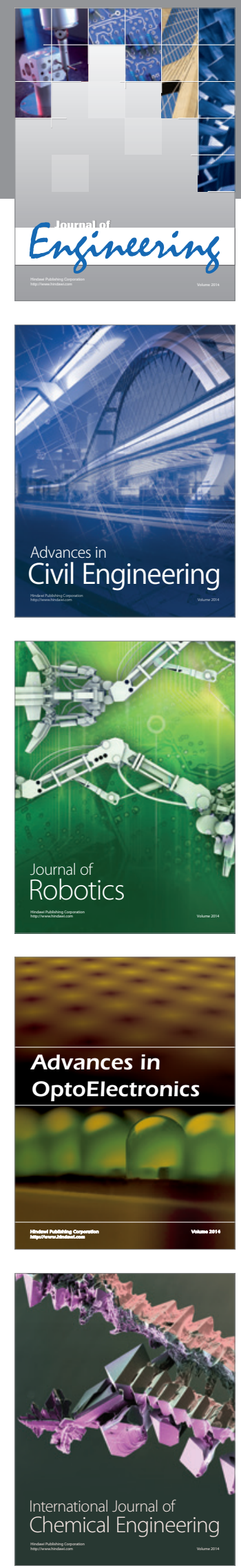

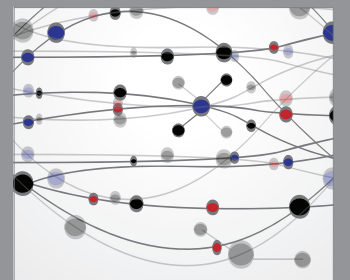

The Scientific World Journal
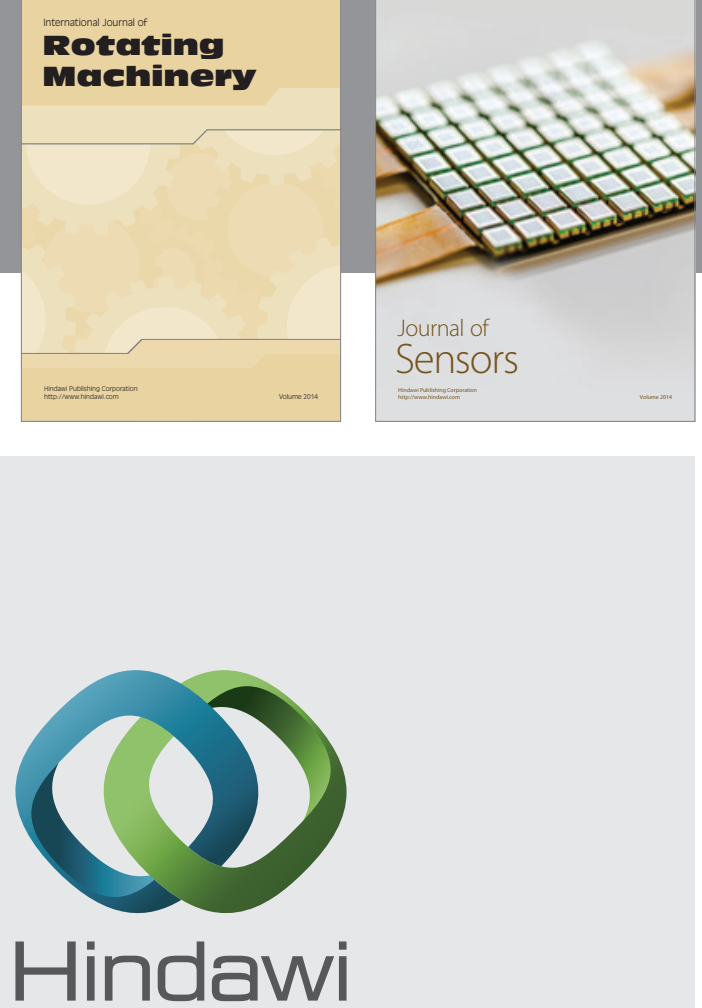

Submit your manuscripts at http://www.hindawi.com
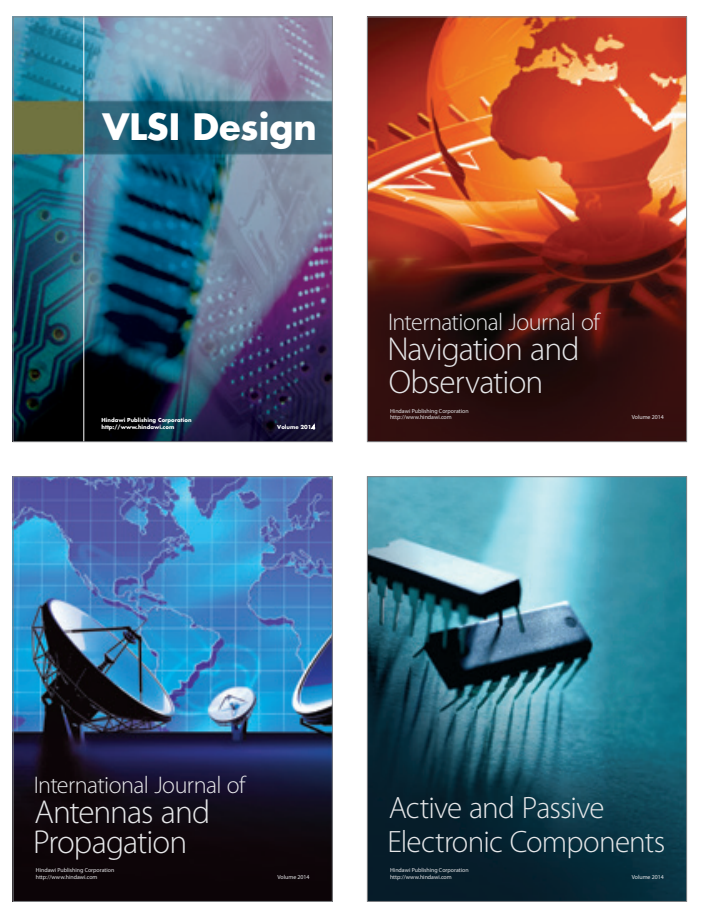
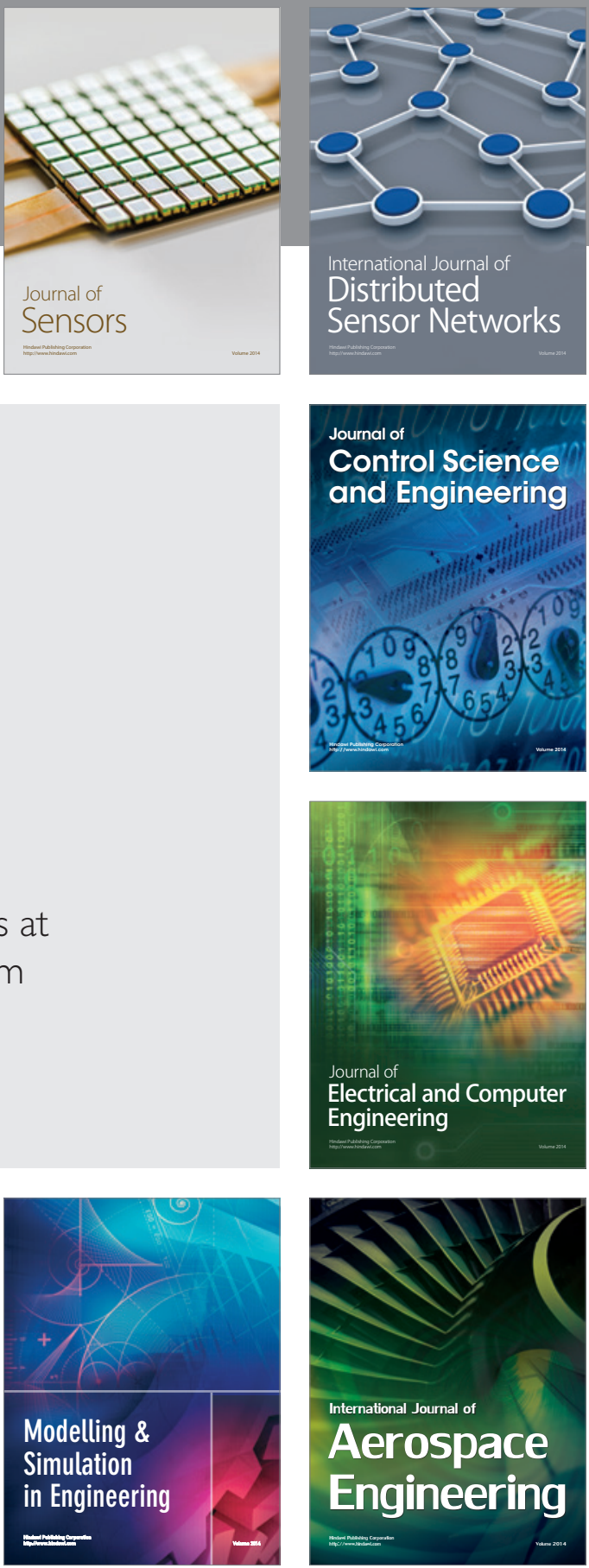

Journal of

Control Science

and Engineering
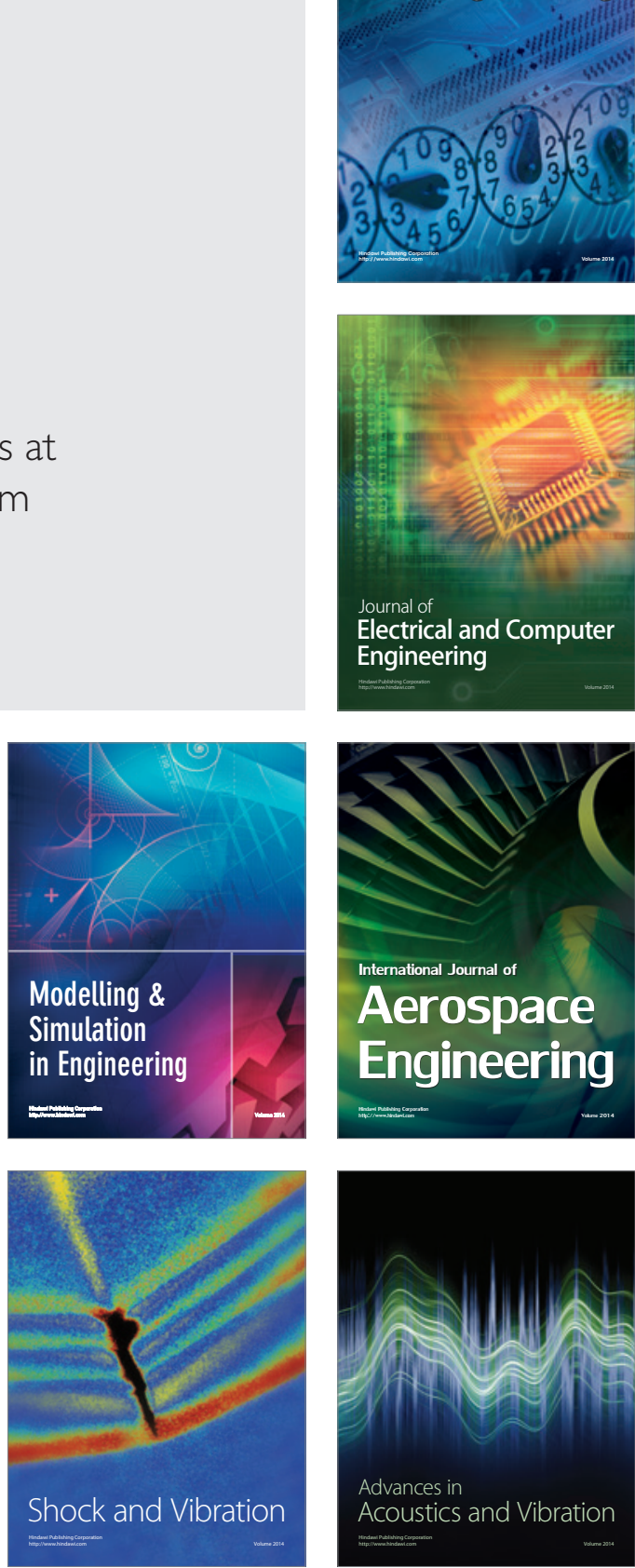